\title{
High performance ion-exchange chromatography of amino-acids in biological fluids using Chromakon 500 - performance of the apparatus
}

\author{
Luc Cynober, Colette Coudray-Lucas, Frédéric \\ Ziegler and Jacqueline Giboudeau \\ Laboratoire de Biochimie A, Hôpital Saint Antoine, 184, rue du Fg. St. Antoine, \\ 75571 Paris Cedex 12, France
}

\section{Introduction}

The separation and quantitative measurement of aminoacids by ion-exchange chromatography has been in use for many years [1]. However, the value of this method is limited by the time required for the analysis: 6 to $23 \mathrm{~h}$. Other methods, such as gas chromatography, give results more rapidly, but do not allow the separation of all amino-acids [2]. The development of cation-exchange resins, capable of resisting high pressure, considerably shortens the time required to perform an analysis. In this study the performance of the Chromakon 500 (Kontron, Switzerland) with a cation-exchange resin (Kontron AS-70 [3]) is evaluated; 39 amino-acids and derivatives can be separated in less than $130 \mathrm{~min}$ (170 min including the regeneration time).

\section{Material and methods}

All the reagents necessary for the ion-exchange chromatography were supplied by Merck (Darmstadt, FR Germany). Stabilized lyophylized serum (set $\mathrm{Hw}$ ) was provided by Bio Merieux (Charbonnières les Bains, France). The 40 amino-acid standard solution was supplied by Pierce and was supplemented with glutamine (final concentration $250 \mu \mathrm{mol} / \mathrm{l}$ ) from Calbioehem (San Diego, California, USA). Amino-acids were separated on the Chromakon 500 equipped with an automatic injection loop, a $15 \mathrm{~cm}$ column packed with Kontron AS 70 resin (diameter $7 \mu$ ) and with five citrate buffers (see table 1). A simplified diagram of the apparatus is given in figure 1. The elution program was a slightly modified version of that given by Kontron (table 2) with modifications which improved the separation of the following amino-acids: cysteine and methionine, cystathionine and isoleucine, 3- methylhistidine and anserine. Detection was performed by colorimetry at $570+440 \mathrm{~nm}$ with the ninhydrin reaction.

The apparatus was coupled to a Shimadzu CR 1 B integrator and amino-acid concentrations were calculated by the method of pic areas. Prior to analysis, stabilized serum was deproteinized by sulphosalicylic acid $(50 \mathrm{mg} / \mathrm{ml}$ serum) and half diluted in buffer 1 .

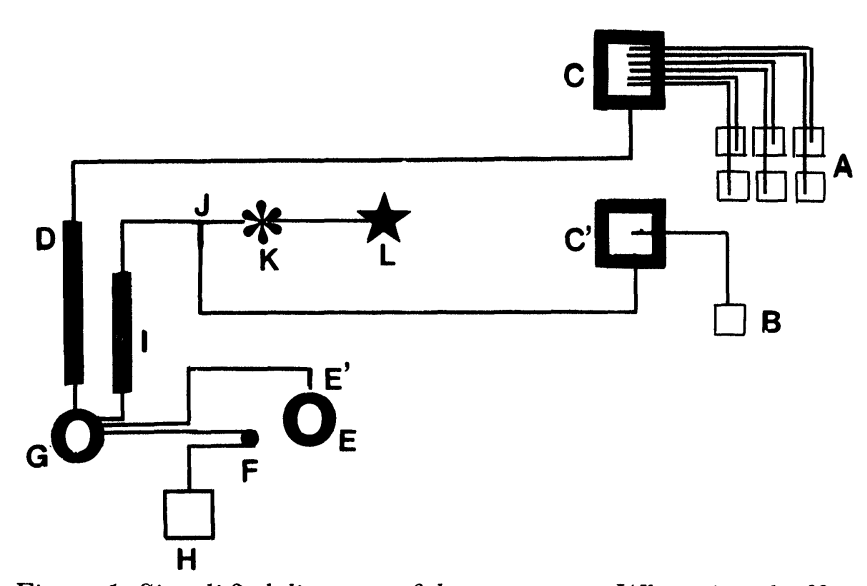

Figure 1. Simplified diagram of the apparatus. Where $A=$ buffer reserves; $B=$ ninhydrin reserve; $C=$ piston pumps $(C=$ buffer, $C^{\prime}=$ reagent $) ; D=$ buffer purification column; $E=$ sample circlet; $E^{\prime}=$ sample needle; $F=$ peristaltic pump; $G=$ injection loop; $H=$ rinsing solution reserves (methanol); $I=$ cationexchange column; $J=$ eluate $/$ ninhydrin $T$-junction; $K=$ oven; $L$ $=$ photometer.

\section{Results and discussion}

The stability of retention times was studied by 10 consecutive injections of the calibration solution. Aminoacids were adequately separated (a typical chromatogram is shown in figure 2). Retention times are constant: GVs ranged from 0.1 to $1.5 \%$ (table 3 ) and are rather better than those provided by liquid HPLC [4]. When the apparatus is stopped, it is interesting to note that a $1 \mathrm{~h}$ equilibration time with buffer 1 is required before performing the first analysis in order to obtain constant retention times.

Table 1. Composition of buffers.

\begin{tabular}{lccccc}
\hline & 1 & 2 & 3 & 4 & 5 \\
\hline Lithium hydroxide & & & & & \\
$\quad$ monohydrate (g) & $5 \cdot 05$ & $5 \cdot 45$ & $8 \cdot 4$ & $8 \cdot 4$ & $8 \cdot 4$ \\
Citric acid monohydrate (g) & $17 \cdot 4$ & $17 \cdot 4$ & $17 \cdot 4$ & $17 \cdot 4$ & $14 \cdot 7$ \\
Lithium chloride (g) & 0 & 0 & 0 & 16 & 35 \\
Chlorhydric acid (ml) & 19 & 15 & 20 & 8 & - \\
Phenol (ml) & 2 & 2 & 2 & 2 & 2 \\
Methanol (ml) & 70 & 50 & - & - & -
\end{tabular}

Purified water, quantity

for 11

The buffers were filtered, degassed, and left for $12 \mathrm{~h}$ before adjusting the $\mathrm{pH}$ to:

$\begin{array}{lllll}2 \cdot 60 & 3 \cdot 10 & 3 \cdot 75 & 4 \cdot 0 & 5 \cdot 25\end{array}$




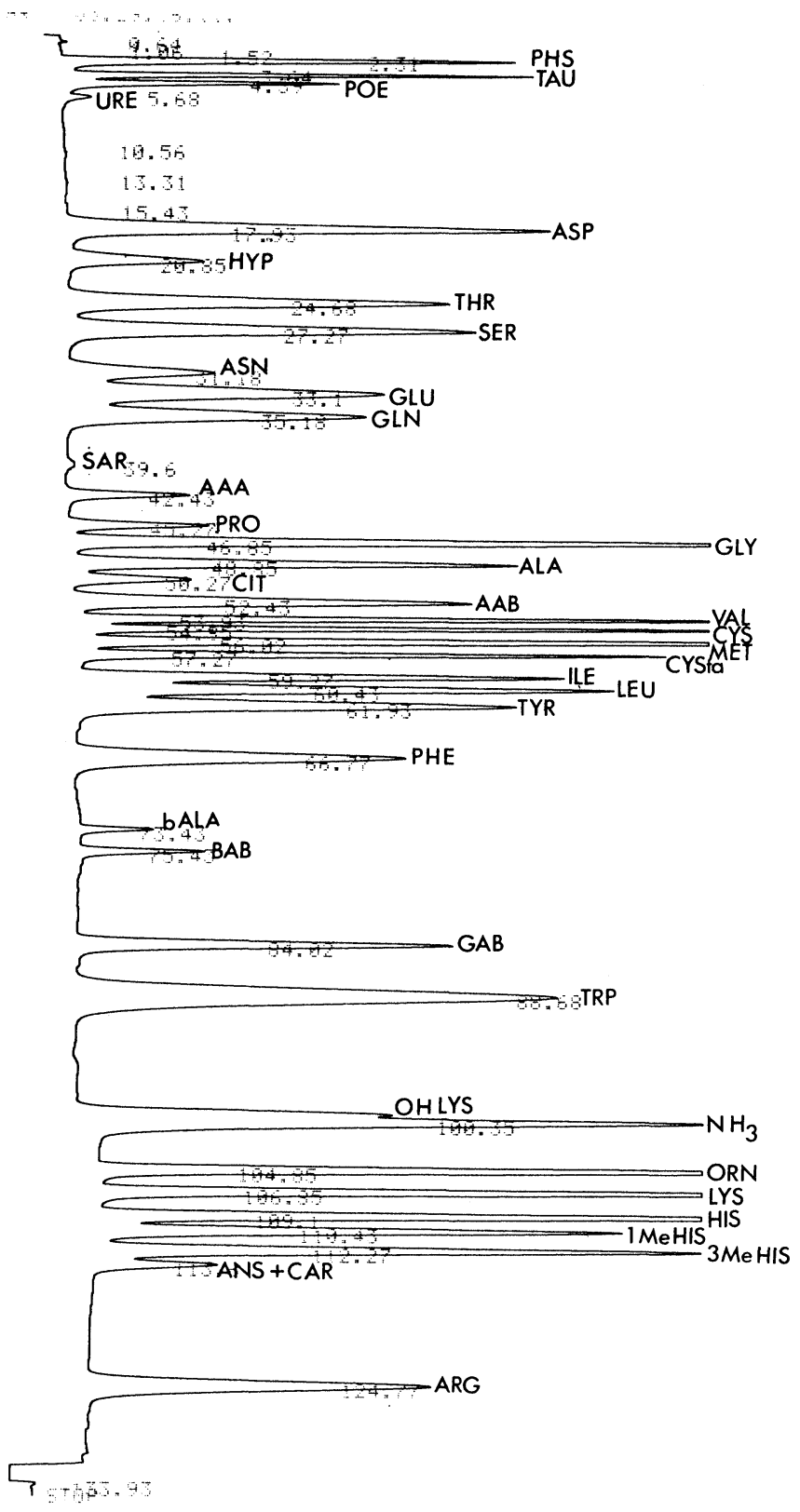

Figure 2. A typical chromatogram obtained with the standard solution supplemented with glutamine. Where PHS = phosphoserine, TAU = taurine, POE: phosphoethanolamine, $U R E=$ urea,$A S P=$ aspartic acid, $H Y P=$ hydroxyproline, $T H R=$ threonine,$\quad S E R=$ sérine,$\quad A S N=$ asparagine, $G L U=$ glutamic acid, $G L N=$ glutamine, $A L A=$ alanine, $S A R=$ sarcosine, $A A A=$ alpha aminoadipic acid, $P R O=$ proline, $\quad G L Y=$ glycine,$\quad V A L=$ valine,$\quad C Y S=$ cysteine , $M E T=$ methionine,$C Y S T a=$ cystathionine,$\quad I L E=$ isoleucine, $L E U=$ leucine, $T Y R=$ tyrosine, $P H E=$ phenylalanine, $b A L A=\beta$ alanine, $B A B=\beta$ aminoisobutyric acid, $G A B=\gamma$ aminobutyrique acid, $\quad T R P=$ tryptophane, $O H \quad L Y S=$ hydroxylysine, $\quad \mathrm{NH}_{3}=$ ammoniac, $\quad O R N=$ ornithine, LYS = lysine, HIS = histidine, $1 \mathrm{MeHIS}=1$-methylhistidine, $3 \mathrm{MeHis}=3$ methylhistidine, $A N S+C A R=$ anserine + carnosine, $A R G=$ arginine.

Linearity and detection limit assays were performed by dilutions of the standard ( 2500 or $1250 \mu \mathrm{mol} / \mathrm{l}$ according to the amino-acids, $500,250,125,50,25,10$ and 5
Table 2. Elution of amino-acids.

\begin{tabular}{|c|c|c|}
\hline Passage time of buffer 1 & 0 & $\min$ \\
\hline $\mathrm{pH}$ of buffer 1 & $2 \cdot 60$ & \\
\hline lst temperature & $35^{\circ} \mathrm{C}$ & \\
\hline Cooling stopped & 34 & $\min$ \\
\hline Passage time of buffer 2 & 11 & $\min$ \\
\hline $\mathrm{pH}$ of buffer 2 & $3 \cdot 10$ & \\
\hline 2nd temperature & $62^{\circ} \mathrm{C}$ & \\
\hline 2nd temperature at & 37 & $\min$ \\
\hline Passage time of buffer 3 & 43 & $\min$ \\
\hline $\mathrm{pH}$ of buffer 3 & $3 \cdot 75$ & \\
\hline Passage time of buffer 4 & 66 & $\min$ \\
\hline pH of buffer 4 & $4 \cdot 00$ & \\
\hline Passage time of buffer 5 & 97 & $\min$ \\
\hline $\mathrm{pH}$ of buffer 5 & $5 \cdot 25$ & \\
\hline 3rd temperature & $70^{\circ} \mathrm{C}$ & \\
\hline 3rd temperature at & 88 & $\min$ \\
\hline Time buffer 6 (regeneration) & 127 & $\min$ \\
\hline Column cooling time & 135 & $\min$ \\
\hline Return-time buffer 1 & 138 & $\min$ \\
\hline
\end{tabular}

N.B.: Times given are from the beginning of the analysis.

$\mu \mathrm{mol} / \mathrm{l})$. The reaction was linear to a concentration of at least $1250 \mu \mathrm{mol} / \mathrm{l}$, which is higher than usual plasma and urine concentrations for all amino-acids given that samples are half-diluted before analysis. The detection limit was less than $5 \mu \mathrm{mol} / \mathrm{l}$, except for glutamate and glutamine $(10 \mu \mathrm{mol} / 1)$ and phenylalanine $(25 \mu \mathrm{mol} / 1)$.

Repeatability assays performed by 10 consecutive measurements of amino-acid contents of a lyophylized serum (HW Unitrol) gave good results (table 3 ). The CV of all amino-acids was under $5 \%$, except for phenylalanine $(8 \cdot 3 \%)$. Reproducibility assays performed with HW Unitrol serum measured in 10 different series, gave a mean coefficient of variation of $10.2 \%$. The comparatively poor results concern proline $(17 \cdot 6 \%)$. These results are comparable to those obtained by liquid-liquid HPLC [4] and classic ion-exchange chromatography [5], but are not quite as good as those obtained by gas chromatography [6].

In conclusion, this apparatus gives precise results for physiological amino-acids in a reasonably short time, so the use of this high-performance ion exchange chromatography is very attractive.

A useful feature is that the analysis program can be modifed at all times. Similarly, the creation of new programs is very simple, for example the program can be shortened if one is particularly interested in the aminoacids. Breakdowns are infrequent, provided the apparatus is regularly maintained. Special attention should be paid to cleaning the air filter supplying cooling air to the electronic circuitry. The flow of ninhydrin must be stopped when passing the regeneration buffer because the liberation of certain very ninhydrin-sensitive substances leads to the formation of crystals which block the system.

The blockage of the separation and purification columns can be avoided by inverting them every two months. Column-life is very satisfactory: the same column has been in use for more than 18 months. Finally, it is worth noting that the equipment is more reliable if it is in continuous use. 
Table 3. Stability of retention time, repeatability and reproducibility assays.

\begin{tabular}{|c|c|c|c|c|c|c|}
\hline $\begin{array}{l}\text { Amino- } \\
\text { acid }\end{array}$ & $\begin{array}{c}\text { Retention time } \\
\overline{\mathrm{x}} \pm \mathrm{SD} \\
(\text { minutes })\end{array}$ & CV\% & $\begin{array}{l}\text { Repeatability } \\
(N=10) \\
\overline{\mathrm{x}} \pm \mathrm{SD} \\
(\mu \mathrm{mol} / \mathrm{l})\end{array}$ & $\mathrm{CV} \%$ & $\begin{array}{l}\text { Reproducibility } \\
\quad(N=10) \\
\overline{\mathrm{x}} \pm \mathrm{SD} \\
(\mu \mathrm{mol} / \mathrm{l})\end{array}$ & GV\% \\
\hline PHS & $2 \cdot 17 \pm 0 \cdot 02$ & $0 \cdot 9$ & $25 \pm 0.9$ & $3 \cdot 6$ & $29 \pm 2$ & $8 \cdot 4$ \\
\hline TAU & $3.72 \pm 0.02$ & 1.5 & $91 \pm 2 \cdot 3$ & $2 \cdot 5$ & $72 \pm 15$ & $11 \cdot 1$ \\
\hline ASP & $17.83 \pm 0.21$ & $1 \cdot 2$ & $58 \pm 1 \cdot 1$ & 1.8 & $40 \pm 5$ & $12 \cdot 5$ \\
\hline HYP & $20 \cdot 63 \pm 0 \cdot 16$ & $0 \cdot 2$ & $<5$ & & $<5$ & \\
\hline THR & $24.55 \pm 0.15$ & $0 \cdot 6$ & $77 \pm 2 \cdot 8$ & $3 \cdot 6$ & $78 \pm 7$ & $9 \cdot 3$ \\
\hline SER & $27 \cdot 27 \pm 0 \cdot 15$ & $0 \cdot 6$ & $56 \pm 2 \cdot 3$ & $4 \cdot 1$ & $70 \pm 7$ & $9 \cdot 5$ \\
\hline ASN & $38.46 \pm 0.27$ & $0 \cdot 7$ & $<5$ & & $<5$ & \\
\hline GLU & $39.53 \pm 0.33$ & $0 \cdot 8$ & $107 \pm 2 \cdot 8$ & $2 \cdot 6$ & $137 \pm 14$ & $10 \cdot 2$ \\
\hline GLN & $40 \cdot 26 \pm 0 \cdot 24$ & $0 \cdot 6$ & $29 \pm 1 \cdot 0$ & $3 \cdot 4$ & $72 \pm 8$ & $11 \cdot 1$ \\
\hline PRO & $49 \cdot 85 \pm 0.34$ & $0 \cdot 7$ & $75 \pm 1 \cdot 8$ & $2 \cdot 4$ & $90 \pm 16$ & $17 \cdot 6$ \\
\hline GLY & $51 \cdot 45 \pm 0.36$ & $0 \cdot 7$ & $304 \pm 2 \cdot 5$ & $0 \cdot 8$ & $333 \pm 31$ & $9 \cdot 3$ \\
\hline ALA & $53 \cdot 13 \pm 0 \cdot 48$ & $0 \cdot 9$ & $306 \pm 5 \cdot 2$ & $1 \cdot 7$ & $271 \pm 22$ & $7 \cdot 9$ \\
\hline CIT & $54.45 \pm 0.38$ & $0 \cdot 7$ & $53 \pm 2 \cdot 0$ & $3 \cdot 5$ & $55 \pm 5$ & $10 \cdot 0$ \\
\hline VAL & $59 \cdot 83 \pm 0.45$ & $0 \cdot 8$ & $232 \pm 4 \cdot 5$ & 1.9 & $213 \pm 20$ & $9 \cdot 4$ \\
\hline CYS & $62 \cdot 99 \pm 0 \cdot 36$ & $0 \cdot 6$ & $<5$ & & $<5$ & \\
\hline MET & $63 \cdot 81 \pm 0 \cdot 35$ & $0 \cdot 5$ & $31 \pm 0 \cdot 4$ & $1 \cdot 3$ & $29 \pm 3$ & $10 \cdot 3$ \\
\hline ILE & $65 \cdot 51 \pm 0 \cdot 85$ & $1 \cdot 3$ & $93 \pm 2 \cdot 0$ & $2 \cdot 2$ & $78 \pm 8$ & $10 \cdot 0$ \\
\hline LEU & $67 \cdot 21 \pm 0 \cdot 36$ & $0 \cdot 5$ & $199 \pm 2 \cdot 8$ & $1 \cdot 3$ & $162 \pm 13$ & $8 \cdot 2$ \\
\hline TYR & $68 \cdot 25 \pm 0 \cdot 11$ & $0 \cdot 2$ & $41 \pm 1 \cdot 8$ & $4 \cdot 4$ & $43 \pm 5$ & $11 \cdot 6$ \\
\hline PHE & $72 \cdot 83 \pm 0.45$ & $0 \cdot 6$ & $63 \pm 5 \cdot 0$ & $8 \cdot 3$ & $62 \pm 5 \cdot 5$ & 8.9 \\
\hline TRP & $91 \cdot 80 \pm 0.52$ & $0 \cdot 6$ & $39 \pm 0.7$ & $1 \cdot 8$ & $36 \pm 3$ & $8 \cdot 5$ \\
\hline ORN & $106.27 \pm 0.50$ & $0 \cdot 5$ & $114 \pm 1.5$ & $1 \cdot 3$ & $86 \pm 10$ & $11 \cdot 6$ \\
\hline LYS & $108 \cdot 51 \pm 0.43$ & $0 \cdot 4$ & $133 \pm 2 \cdot 3$ & 1.7 & $118 \pm 15$ & $12 \cdot 7$ \\
\hline HIS & $110 \cdot 79 \pm 0.21$ & $0 \cdot 2$ & $86 \pm 1 \cdot 4$ & $1 \cdot 6$ & $78 \pm 7 \cdot 5$ & $9 \cdot 6$ \\
\hline ARG & $126.73 \pm 0.06$ & $0 \cdot 1$ & $169 \pm 4 \cdot 6$ & $2 \cdot 7$ & $140 \pm 11$ & $7 \cdot 6$ \\
\hline
\end{tabular}

\section{References}

1. Moore, S. and Stein, W. H., Journal of Biological Chemistry, 211 (1954), 893

2. Cynober, L., Blonde, F., Nguyen Dinh, F., Gerbet, D. and Giboudeau, J., Annales de Biologie Clinique, 41 (1983), 33
3. Hughes, G. J. and Wilson, K. J., Journal of Chromatography, 242 (1982), 337.

4. Biggs, H. G. and Gentrilgore, L. J., Clinical Chemistry, 30 (1984), 851.

5. Castets, J. C., Parvy, P. and Huang, Y., Annales de Biologie Clinique, 39 (1981), 45.

6. Yamamoto, S., Kiyama, S., Watanabe, Y. and Makita, M., Journal of Chromatography, 233 (1982), 39.

\section{FOOD ADDITIVES \& CONTAMINANTS}

Now in its third volume, this Taylor \& Francis journal contains original research and review articles relating to the detection, determination, occurrence, persistence, safety evaluation and control of naturally occurring and man-made additives and contaminants in the food chain.

Contributions include aspects of the chemistry, biochemistry and bioavailability of these substances, their metabolites or reaction products; advances in analytical methodology; and factors affecting levels of potentially toxic compounds which may arise during processing, packaging and storage.

Recent articles include:

Sulphiting agents in foods: some risk/benefit considerations

R. Walker, UK

The absence of rhamnose in human urine following the ingestion of gum karaya (Sterculia)

A. W. J. Anderson et al.,

Chromium in foods and the diet

G. A. Smart and J. C. Sherlock, UK

Naturally occurring oestrogens in foods - a review

K. R. Price and G. R. Fenwick, UK

Interaction between plastics packaging materials and foodstuffs

W.-D. Bieber, K. Figge and J. Koch, FR Germany

Sample copies from Taylor \& Francis. 


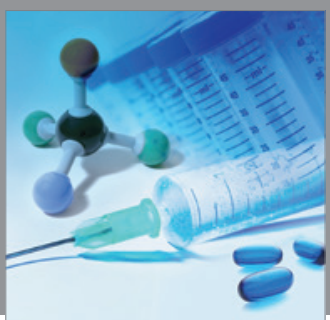

International Journal of

Medicinal Chemistry

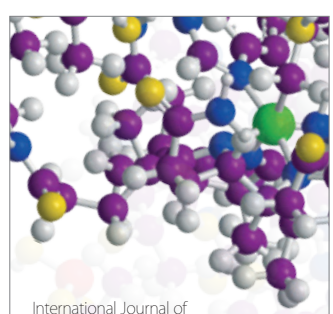

Carbohydrate Chemistry

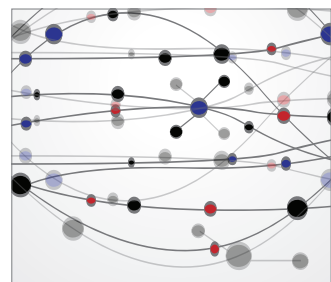

The Scientific World Journal
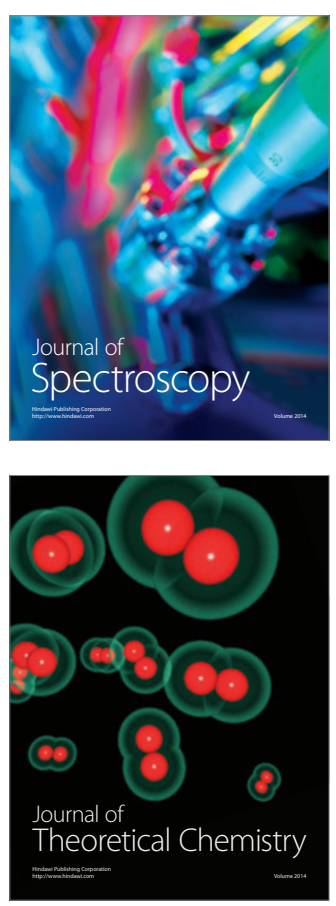
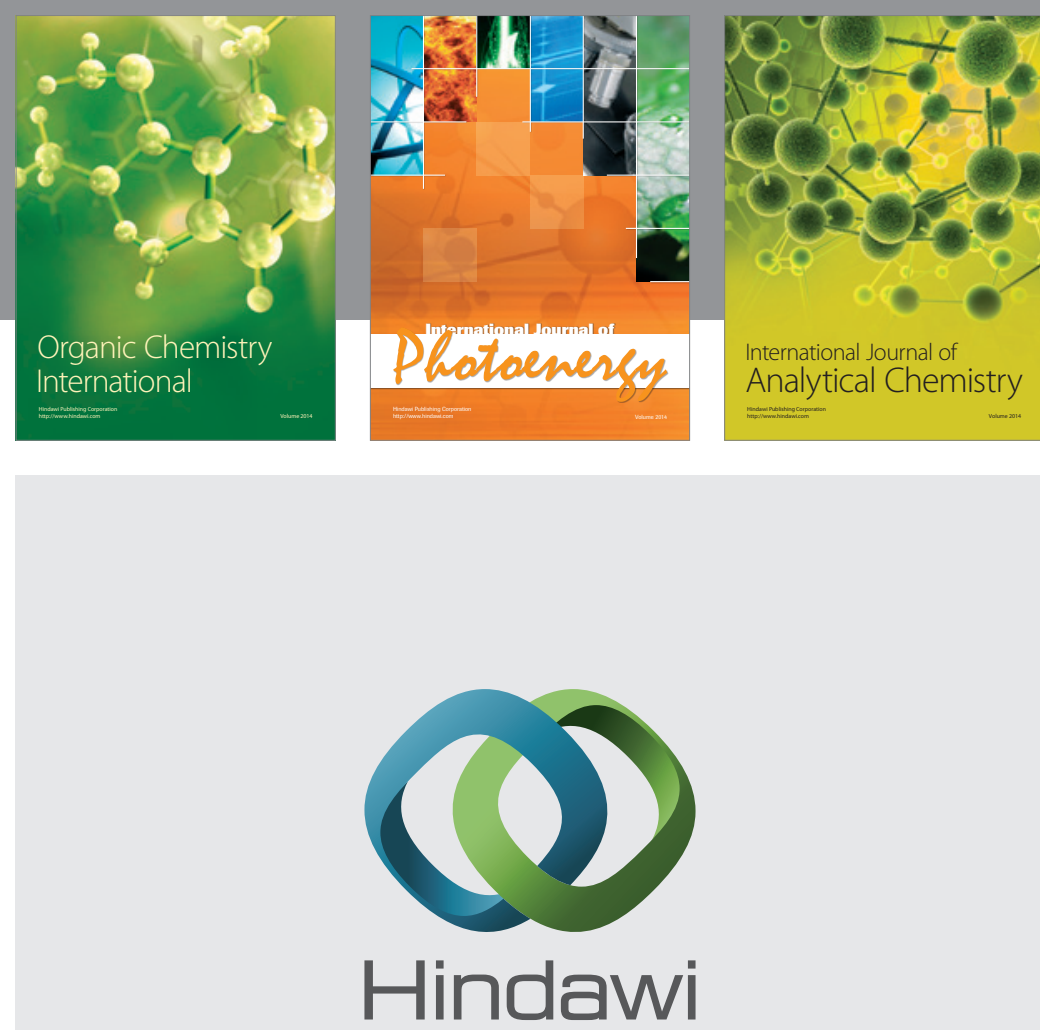

Submit your manuscripts at

http://www.hindawi.com
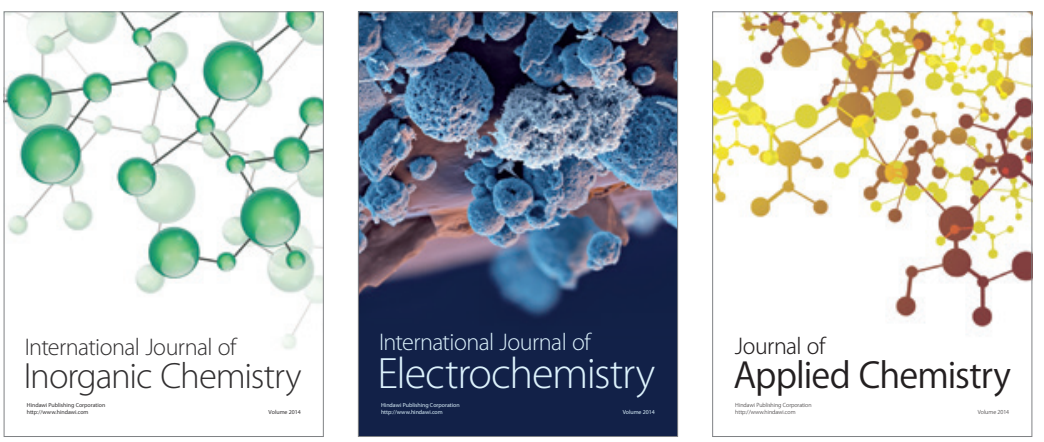

Journal of

Applied Chemistry
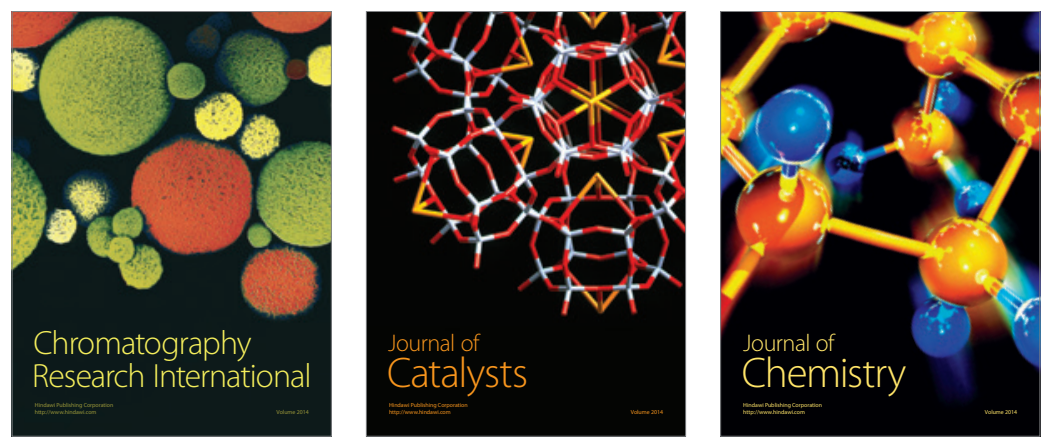
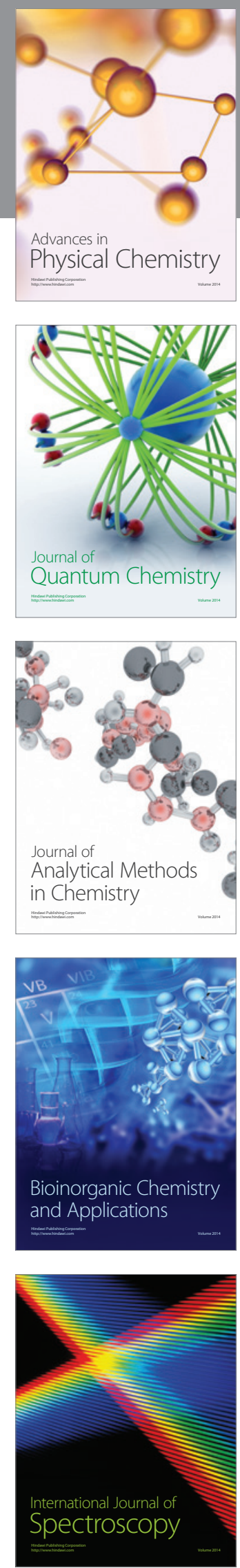